Perspective

\title{
Navigating around parenting blind spots when raising challenging children
}

Volume 9 Issue I - 2018

\section{Perspective}

The challenges of raising challenging children can turn the parenting journey into a potential minefield of mistakes and mishaps. The most well meaning and brightest of parents sometimes feel that they should have known better, better anticipated, not said this or that, or some combination thereof. Certainly some mistakes can't be avoided while others can be prevented with proper navigational assistance.

If your parent driving record includes too many violations of common sense or blind spot accidents outside of your awareness, read on for a smoother ride:

Look out for one of the most common blind spots: unnecessary engagement. This occurs when your child is experiencing some frustration with an issue and is "mentally wrestling" with it. Typically, this expresses itself through complaining, over-persistence, and/or constant discussion about the issue. Unnecessary engagement occurs when parents can't resist the urge to verbally join in by restating the obvious, hammering away about the lessons to be learned or expanding the discussion to include other related and upsetting past events. This is tantamount to offering oneself as the opponent at a time when your child is doing what they need to do: finding some closure on their own. All the frustration the child is experiencing gets focused on the parent, and the outcome is further strain placed upon the relationship.

A second blind spot entails the tendency to pursue a line of questioning (known as accusing in the child's mind) that is destined to cause parents to lose their composure and in doing so, their intended direction. As tough issues mount with difficult kids it is even tougher to stay calm, focused, and strike a balance between understanding the child's view and expressing one's own. Due to a harsh accusatory tone, some parents drive full speed into the trap of their own self-fulfilling prophesies. Typically, the parent's internal narrative is akin to "My child lies to me, disrespects me, takes advantage, won't take responsibility, etc." When circumstances heat up, these thoughts further fuel parental anger, and then trigger these reactions in the child.

A third blind spot is especially troubling to parental credibility: ignorance of one's own issues. This occurs when a parent has failed to take inventory of their own emotional hot spots, biases, and assorted shortcomings. At the same time, these personal limitations are very obvious to family members, including one's spouse, extended rela-

\author{
Steven Richfield \\ Clinical Psychologist, Philadelphia, USA
}

Correspondence: Steven Richfield, Clinical Psychologist,
Philadelphia, USA, Tel 610-238-4450, Email director@parentcoachcards.com

Received: February 28, 2017 | Published: January 04, 2018 tives, and especially children that enjoy pushing buttons. This combination of parental denial and challenging child is particularly toxic to family harmony. These parents will often see family problems as entirely the fault of the child, forfeiting all responsibility, yet expecting the child to accept it all.

Minimizing problems is another form of parenting denial but this hot spot involves seeing problems through rose colored glasses. Parents blinded by the need to see their child's problems as "just a phase," comforting themselves with the notion that "I turned out ok" or using the empty rationalization of "I don't believe in getting help," are doing a great disservice to their child. Such parents are those that often look back upon their parenting journey with guilt and dismay about having abdicated their role to help their children heal when necessary.

\section{Acknowledgements}

None.

\section{Conflict of interest}

Author declares there are no conflicts of interest.

\section{Funding}

None. 